\title{
Exploring Four-Star vs Two-Star Hotel Guests' Online Reviews: An Attitude Analysis in Appraisal Framework
}

\author{
Nina Setyaningsih ${ }^{1}$, Dwi Vicky Leksono ${ }^{2}$, Mafika Rusnawati ${ }^{3}$ \\ \{nina.setyaningsih@dsn.dinus.ac.id ${ }^{1}$,dwivicky68@gmail.com² ${ }^{2}$ mafikars@gmail.com ${ }^{3}$ \} \\ Universitas Dian Nuswantoro, Indonesia ${ }^{1,2,3}$
}

\begin{abstract}
This research analyzes the reviews written by guests staying at four-star and two-star hotels in Semarang. It is aimed at examining whether there are similarities or differences in how guests expressed their attitude towards their experiences after staying at the hotels. The research employed the Appraisal framework proposed by Martin and White [1], focusing on the Attitude system consisting of Affect, Judgment, and Appreciation. The data were obtained from guest's reviews downloaded from Traveloka website. The data were taken then analyzed qualitatively by describing the guests' attitudes towards the hotel services. The results reveal that the guests demonstrate judgment, appreciation, and affect in their reviews. Both hotels also received positive and negative reactions from the guests. Hotel guests are mostly satisfied with the low price and facilities/services given by the two-star hotel. On the contrary, the guests have high expectations since they spend more money in the four-star hotel. In addition, based on the average rating (with 10 being the highest), the two-star hotel had a slightly higher score than the four-star hotel. This research indicates that hospitality industries can take the advantage be a useful as a tool to generate valuable inputs for the improvement of hotel and tourism industries.
\end{abstract}

Keywords: Appraisal, Attitude, Hotel, Reviews

\section{Introduction}

The rapid development of technology has changed the way people do their activities. In this era of Internet, people can easily do these activities online. As a case in point, when they need to book accommodation or transportation services, they do not have to directly come to the accommodation or transportation offices or make a phone booking. Instead, they can simply go to websites or smartphone applications to do that as long as they have an Internet connection. In Indonesia, several well-known websites and applications include Traveloka, Booking.com, Agoda, RedDoorz, Mister Aladdin, and Ticket.com.

As for accommodation service, various types of hotels are frequently chosen and are easily found online. Classes of hotel services are divided into several categories. It can be seen from the number of their stars, for example, one star, two star, and so forth. Normally, the more stars a hotel has, the more famous and the more expensive it is. Also, hotel guests think that hotels having more stars will provide better services. It is common that guests choose a hotel based on its star to suit their needs or budget. The internet era has made people easier to consider hotels' quality of hospitality and service based on the reviews written by previous 
guests. This is because Traveloka and other similar websites or applications provide rating and review options in the platform. Hence, future hotel guests usually read this review to consider what prices and what kind of service the hotels offer and finally decide whether they are going to stay in those hotels.

Related to this phenomenon, this research explores the service evaluation made by guests staying in two different hotels in Semarang (Central Java, Indonesia) through their reviews. The reviews were taken from a two-star hotel and a four-star hotel in Traveloka website (https://www.traveloka.com). Specifically, this research investigates the appraisal system of Attitude of the guests' reviews of each hotel.

Studies have been conducted on Appraisal - Attitude of different types of text, among others by Liu [2] and Setyaningsih and Larassati [3] in English as Foreign Language (EFL) teaching and learning setting, and Dong and Lin [4] in poems. Liu [2] analyzed the English argumentative writing of EFL students. The research found that the high-rated students' writings used appraisal items successfully to foreground their voice and to position the readers which results in manipulating the arguability of the utterances and building firm persuasion. Meanwhile, the study conducted by Setyaningsih and Larassati [3] revealed that students' positive and negative reviews on the way the grammar teacher taught were able to give inputs to the teacher, and it suggested that the findings might be useful as a tool for the teacher to decide which teaching and learning strategies to be used. Different from the two previous studies, Dong and Lin [4] conducted a contrastive analysis of appraisal in two English versions of a Chinese poem. The study not only revealed the similarities and differences of the attitudinal resources but also presented that Appraisal theory is applicable to analyze the translation of poems.

As previously mentioned, in this research, the researchers limit their study into Appraisal system of Attitude. Appraisal belongs to the field of Systemic Functional Linguistics (SFL). Appraisal is associated with interpersonal meanings. This framework is often employed to analyze texts by seeing their structures and meanings. Appraisal allows for analysis of meanings conveyed by texts [1]. One subsystem of Appraisal, Attitude, is usually used to express someone's good or bad feelings and thoughts [5]. Attitude can be categorized into three sub sets, viz. Affect, Judgment, and Appreciation [1]. Affects is related to positive and negative feelings. It concerns whether one feels happy/unhappy, confident/anxious, or interested/bored. Judgment involves one's attitude towards behavior: admire/criticize, or praise/condemn. Appreciation deals with evaluations of natural phenomena, whether they are valued or not in a certain field. Simply put, the system of Attitude is presented in the following figure:

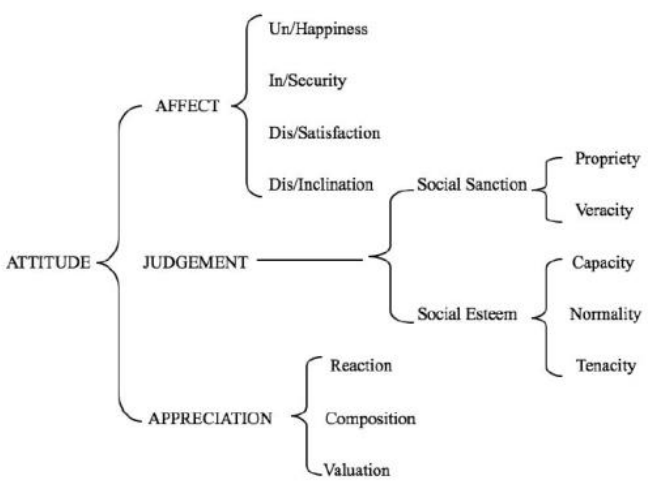

Fig. 1. Appraisal - Attitude [6]. 


\section{Methodology}

This research is a descriptive qualitative one as it describes how hotel guests' attitude were realized in their reviews. The data were taken from the Traveloka website, accessible at https://www.traveloka.com. The guests' reviews of two hotels with different stars in the website were gathered. The research examined reviews from a four-star hotel and a two-star hotel in Semarang, simply referred to as $4 *$ HOTEL and $2 *$ HOTEL respectively for the sake of confidentiality of the research subjects. Reviews appearing in the first five pages were taken to be analyzed. The unit of analysis in this research included elements such as words, phrases, and clauses containing attitudinal devices. After that, they were categorized into the subsystems of Attitude proposed by Martin and White [1].

\section{Findings and Discussion}

This section presents the findings and discussion of the analysis.

\subsection{Findings}

The following tables demonstrates the research findings. Table 1 shows the result of 4*HOTEL review, in which Appreciation dominates the findings (53\%), followed by Judgement (25\%) and Affect (22\%). The average rating given by the guests is 8.44 (out of 10 ).

Table 1. The guests' Attitude towards 4*HOTEL's service

\begin{tabular}{|c|c|c|c|c|c|}
\hline Attitude & Sub-categories & $(+)$ & $(-)$ & Sub-total & $\%$ \\
\hline \multirow[t]{2}{*}{ Affect } & Dis/satisfaction & 22 & 5 & 27 & \\
\hline & Un/happiness & 3 & - & 3 & $22 \%$ \\
\hline \multicolumn{2}{|l|}{ Total of Affect } & & & 30 & \\
\hline \multirow{4}{*}{ Judgment } & Normality & 2 & 2 & 4 & \\
\hline & Capacity & 11 & 13 & 24 & \\
\hline & Tenacity & 1 & 2 & 3 & $25 \%$ \\
\hline & Propriety & 3 & - & 3 & \\
\hline Total of Judgment & & & & 34 & \\
\hline \multirow{2}{*}{ Appreciation } & Reaction & 62 & 9 & 71 & $53 \%$ \\
\hline & Composition & 1 & 1 & 2 & \\
\hline \multirow[t]{3}{*}{ Total of Appreciation } & & & & 73 & \\
\hline & Total & & & 137 & $100 \%$ \\
\hline & ge rating: 8.44 & & & & \\
\hline
\end{tabular}

Meanwhile, Table 2 presents the findings of Attitude in $2 *$ HOTEL. The highest number is Appreciation (68\%), followed by Judgment (18\%) and Affect (14\%). The average rating of $2 *$ HOTEL is 8.5 (out of 10 ), which is slightly higher than that of $4 *$ HOTEL.

Table 2. The guests' Attitude towards 2*HOTEL's services

\begin{tabular}{llccccc}
\hline \multirow{2}{*}{ Attitude } & \multicolumn{2}{c}{ Sub-categories } & \multicolumn{2}{c}{$\sum$} & \multirow{2}{*}{ Sub-total } & \multirow{2}{*}{$\%$} \\
\cline { 3 - 4 } & & $(+)$ & $(-)$ & & \multirow{2}{*}{$14 \%$} \\
\hline Affect & Dis/satisfaction & 8 & 5 & 13 & 1 \\
& Un/happiness & 1 & - & & &
\end{tabular}




\begin{tabular}{llcccc}
\hline & In/security & 1 & - & 1 & \\
& $\begin{array}{l}\text { Dis/inclination } \\
\text { Total of Affect }\end{array}$ & 2 & - & 2 & \\
\hline Judgement & Normality & 2 & - & 2 & \\
& Capacity & 11 & 4 & 15 & \\
& Veracity & - & 1 & 1 & $18 \%$ \\
& $\begin{array}{l}\text { Propriety } \\
\text { Total of Judgment }\end{array}$ & 2 & 3 & 5 & \\
\hline Appreciation & Reaction & 51 & 20 & 72 & \\
& Valuation & 5 & 1 & 6 & $68 \%$ \\
& Composition & 6 & 2 & 8 & \\
\hline Total of Appreciation & & & $\mathbf{8 5}$ & $\mathbf{1 0 0 \%}$ \\
\hline Average rating: $\mathbf{8 . 5 0}$ & & & & $\mathbf{1 2 5}$ & \\
\hline
\end{tabular}

\subsection{Discussion}

The discussion of the data analysis is presented in the following section.

\subsubsection{Similarities and Differences of Attitude in the Hotel Reviews}

Based on the tables of the findings in the previous section, some similarities in the guests' attitude as implied from their reviews of both hotels can be generated. The reviews have similar order of percentages in the Appraisal subsystems, that is, Appreciation ranks the first, followed by Judgment and Affect. Appreciation in the guests' reviews of both hotels refer to the quality of the room and hotel facilities. Meanwhile, Judgment of both hotels concerns with how the staff give service to the guests. As for Affect, the reviews deal with the guests' feelings about their experience when staying at the hotels, especially on the food provided on breakfast and the hotel fare.

Besides similarities, the findings also present several differences, especially on the rating and the negative Judgment. Besides similarities, the findings also present several differences, especially on the rating and the negative Judgment. The 4 *HOTEL has more negative reviews in terms of Capacity compared to that of $2 *$ HOTEL. Some of the negative reviews on Capacity in $4 *$ HOTEL deal with the service and professionalism of the staff, while in $2 *$ HOTEL with the hotel's capability in providing working facilities.

\subsubsection{Attitude in 4*HOTEL and $2 *$ HOTEL Reviews}

The following section describes the Attitude subsystems found in the reviews of $4 *$ HOTEL and $2 *$ HOTEL.

\section{a. Affect}

In the reviews of $4 *$ HOTEL, Affect relates to the guests' personal feelings about the services and facilities and their experience when staying at the hotels. Examples of Affect found in $4 *$ HOTEL reviews can be seen in the excerpts below:

Excerpt 1:

[A18] I really enjoyed it to stay in $4 *$ HOTEL. 
Excerpt 2:

[A16] Great room, love the bed so much

Excerpt 1 and 2 demonstrate that the words enjoyed and love have a positive meaning. These expressions relate to what the guests felt about their stay in the hotel. These comments can be included in affect: happiness. It can be assumed that the guest feels satisfied about the $4 *$ HOTEL service and facilities.

\section{Excerpt 3:}

[A8] I might back to stay at the hotel, but won't order anything from the restaurant.

The above example implies a negative emotion that the guest felt about the food served in the hotel's restaurant despite the positive possibility about the guest's future stay in the hotel. The guest was disappointed because she paid an expensive steak that had pieces of broken glass in it and the hotel staff didn't give satisfying compliment to her inconvenience. Therefore, excerpt 3 is categorized as affect: dissatisfaction.

Meanwhile, the realization of Affect found in $2 *$ HOTEL reviews is presented below. The reviews concern with the guests' feelings towards the hotel's atmosphere and facilities.

\section{Excerpt 4:}

[B7] My favorite place to take a rest.

It can be seen on the bold statement above that the adjective contains positive polarity and it can be classified as affect: satisfaction. It is clear that the guest appraised 2*HOTEL by stating that $2 *$ HOTEL is of his preference.

\section{Excerpt 5:}

[B31] Overall it's good to stay here.

The above statement shows the guest's positive feelings about the hotel. This excerpt can be classified as affect: satisfaction. It can be also assumed that the guest feels satisfied with every service given by $2 *$ HOTEL.

\section{Excerpt 6:}

[B36] It's annoying that it's a lot cooler outside then inside the room. I hope they fix it.

The excerpt above is classified as affect: inclination since it shows that the guest hoped the hotel would fix the temperature problem in her room.

\section{b. Judgment}

Judgment deals with the guests' evaluation towards the way the hotel staffs give service and the hotel's capacity to provide facilities and services.

The following examples present the description of Judgment in 4*HOTEL reviews:

Excerpt 7:

[A14] they have beautiful scenery from the roof top.

[A30] have nice swimming pool with sky pool with view the city of Semarang. 
The above statements contain positive meaning. They are classified as judgement: capacity. It can be seen that the guests evaluate the capability of $4 *$ HOTEL to provide facilities that are able to comfort the guests.

\section{Excerpt 8:}

[A15] we got room with un properly Aircon and can't change the room with twin bed either.

The statement in the excerpt above implies a negative meaning. It is classified as judgment: capacity. The review deals with the capability of $4 * \mathrm{HOTEL}$ to provide accommodation that suited the guest's needs.

Another Judgment can be seen in the following excerpt. It is categorized as judgment: propriety since it deals with what a 4-star hotel should provide. Guests usually pay a more expensive price to stay in a 4-star hotel, so they expect to get a better service. This example shows that $4 *$ HOTEL is unable to provide a proper service to the guest dealing with the access card.

\section{Excerpt 9:}

[A22] the minor is the staff provide only one access/key card, it should be better 2 card provide to guest

The next examples show the realization of Attitude in $2 *$ HOTEL reviews.

\section{Excerpt 10:}

[B9] Located in downtown and near malls

Based on the statement above it can be seen that the words contain positive meaning and it refers to the guest's review about the strategic location of $2 *$ HOTEL. It can be classified as judgement: capacity.

\section{Excerpt 13:}

[B1] I come in early morning and staff with kindliness allow us to stay at Musholah till our driver coming. Staff very kind, the room clean, not so big but comfy, for girls you no need to bring hairdryer because you can borrow from staff hotel and in every corner, you can find water dispenser.

The bold sentence is also classified as judgement: capacity. It shows the guest's positive attitude towards the kindness of the hotel staff and the ease in finding facilities in the hotel.

\section{Excerpt 14:}

[B36] It's annoying that it's a lot cooler outside then inside the room.

The excerpt demonstrates a negative attitude towards the air conditioner in the guest's room. It implies that the service was not good since she expected that her room would be cooler than outside her rooms. 


\section{c. Appreciation}

Appreciation in the reviews of both hotels concern with the quality of the the hotel room and facilities. Some examples of $4 *$ HOTEL are presented, followed by those of $2 *$ HOTEL.

\section{Excerpt 15:}

[A7] Affordable luxury. No bar but a great pool amd gym space at the roof and perfectly kept rooms.

The bold words in the review above demonstrate the guest's positive attitude towards the hotel facilities. It can be assumed that the guest feels so happy when he knows that the facilities were working properly without having relatively any troubles when he stayed at 4*HOTEL.

\section{Excerpt 16:}

[A21] nice view from the pool, clean.

It can be seen clearly that the statement above is positive and it can be categorized as appreciation: reaction. The guest appraises the good view that the guest could see and the cleanliness of $4 *$ HOTEL.

\section{Excerpt 17:}

[4] This hotel's services were bad, not good coordinated, unprofessional.

Negative evaluation is also found in the review of $4 *$ HOTEL, an example is about the service provided by the hotel. It can be categorized as appreciation: composition. The guest expected that a four-star hotel would give excellent services, instead he was served unprofessionally by the staff.

In almost similar vein, $2 *$ HOTEL reviews also express positive and negative attitude from the guests. Some examples are provided in the following section.

\section{Excerpt 18:}

[B3] Worth it for the price. Located on the heart of the city, near Tugu Muda, Semarang Poncol Station, Paragon and other shopping malls. Hot shower was well functioned. I had the best-view room with 2 windows.

\section{Excerpt 19:}

[B31] budget, clean, easy check in, fast respond

It can be seen from the excerpts above that the reviews shows a positive attitude. These can be included in appreciation: valuation. The review suggests that the money the guests spent for staying at $2 *$ HOTEL was equal with the services and facilities they obtained.

\section{Excerpt 20:}

[35] clean bedroom \& bathroom, nice $\&$ friendly service 
Based on the review above, the guest gave positive attitude. This review is categorized appreciation: reaction. It indicates that the guest comments about the good quality of $2 *$ HOTEL rooms and service.

\section{Excerpt 21:}

[B22] 1 minus is: food is spicy, kids cannot eat

The excerpt presents an example of negative evaluation of the meal served in $2 *$ HOTEL. The example can be classified as appreciation: reaction. It is clear that the guest comments about the food which was already served. The food was spicy so the guest's children could not eat. Usually when a family stays at the hotel, they expect the family members to eat with them.

\section{Conclusion}

This study attempts to uncover the attitude of the guests staying in two-star hotel and four-star hotel by applying Appraisal theory. According to the analysis, negative and positive evaluations are found in the reviews of both hotels. The four-star hotel obtained negative attitude in terms of the hotel staff, service, and facilities, whereas the four-star hotel received negative attitude on the service and facilities. Meanwhile, the positive attitude towards the experience of staying in the four-hotel deals with the room comfort, whereas that of the twostar is on its strategic location. It is also worth noting that based on the average rating (10 is the maximum score), the four-star hotel got 8.4 score, whereas the two-star hotel has 8.5. These findings imply that price wise, the guests of the four-star hotel have high expectation since they spend more money for the hotel, while those of the two-star hotel are usually satisfied with the service they get with such a rate. Furthermore, this research suggests that appraisal framework can be useful as a tool to generate valuable inputs for the improvement of hotel/hospitality and tourism industries.

\section{References}

[1] J. R. Martin and P. R. R. White, "Engagement and Graduation: Alignment, Solidarity and the Construed Reader," in The Language of Evaluation, Springer, 2005, pp. 92-160.

[2] X. Liu, "Evaluation in Chinese University EFL Students' English Argumentative Writing: An APPRAISAL Study.," Electron. J. Foreign Lang. Teach., vol. 10, no. 1, 2013.

[3] N. Setyaningsih and A. Larassati, "Delving into Students' Attitude towards Teaching and Learning Process: An Appraisal Analysis of Course," ELLiC 2019, p. 179, 2019.

[4] T. Dong and X. Lin, "Attitude in appraisal theory: a comparative analysis of english versions of changgan xing,” Int. J. Comp. Lit. Transl. Stud., vol. 6, no. 1, pp. 42-49, 2018.

[5] S. Hood, Appraising research: Evaluation in academic writing. Springer, 2010.

[6] L. Xinghua and P. Thompson, "Attitude in students' argumentative writing: A contrastive perspective,” Lang. Stud. Work. Pap., vol. 1, no. 1, pp. 3-15, 2009. 